Supporting Information

\title{
Effects of Dissolved Carbonates and Carboxylates on the Sorption of Thiuram Disulfide Pesticides on Humic Acids and Model Surfaces Panagiota Stathi ${ }^{\#}$, Maria Louloudi ${ }^{\S}$ and Yiannis Deligiannakis ${ }^{\#} *$
}

* Laboratory of Physical Chemistry, Department of Environmental and Natural Resources Management, University of Ioannina, Seferi 2, 30100, Agrinio, Greece

${ }^{\S}$ Section of Inorganic and Analytical Chemistry, Department of Chemistry, University of Ioannina, Ioannina 45110, Greece

Journal: Environmental Science and Technology (ES0630792)

Date 10-2-2007

Supporting Information Available: Figures S1, S2, S3 experimental characterization of the $\mathrm{SiO}_{2} \mathrm{HA}, \mathrm{SiO}_{2} \mathrm{COOH}, \mathrm{SiO}_{2}[\mathrm{COOH}]_{2}$ materials. Figure $\mathrm{S} 4$ surface charge determination. Figure S5 thiram's sorption on SiO2, Figure S6 thiram's sorption on $\mathrm{SiO}_{2}[\mathrm{COOH}]_{2}$, Figure $\mathrm{S} 7$ thiram's sorption isotherms, Figure S8, inhibitory effect of oxalate, formate. Figure S9 sorption data for disulfiram. 


\section{PART I: characterization of the $\mathrm{SiO} 2$ materials}

\section{Characterization of the $\mathrm{SiO}_{2}$-HA.}

Elemental analysis: C, H, N were performed with a Perkin-Elmer series II 2400 microelemental analyzer. The loading was estimated by thermogravimetric (TGA) analysis performed using a Schimadzu DTG-60 analyzer. The loading achieved for HA is $96 \mathrm{mg}$ of HA per gram of silica i.e. $9.6 \% \mathrm{w} / \mathrm{w}$. This is within the typical loading range reported previously by Koopal et al. (10).

ATR-FTIR and FTIR measurements: Attenuated Total Reflection (ART)-FTIR measurements were performed on aqueous humic acid and aqueous suspensions for $\mathrm{SiO}_{2}$-HA using a PerkinElmer equipped with a horizontal attenuated total reflectance and a ZnSe crystal. All FT-IR spectra were recorded on a Spectrum GX Perkin-Elmer FT-IR System. The ATR-FTIR spectra of humic acid and the immobilized humic acid are shown in Figure $\mathrm{S} 1$.

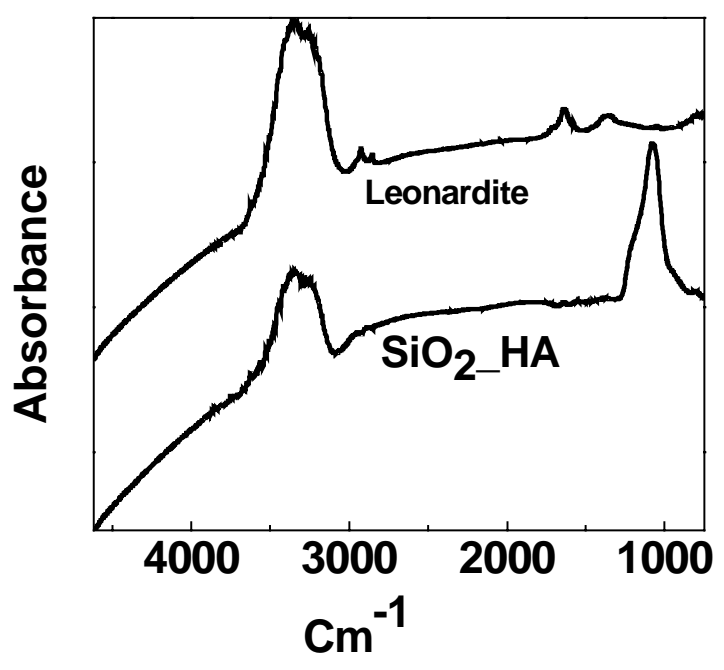

Figure S1. ATR-FTIR spectra of $\mathrm{HA}$ and $\mathrm{SiO}_{2}-\mathrm{HA}$ 
The Diffuse Reflectance-FTIR spectra for the modified $\mathrm{SiO}_{2}-(\mathrm{COOH})_{2}$ material.are shown in Figure S2

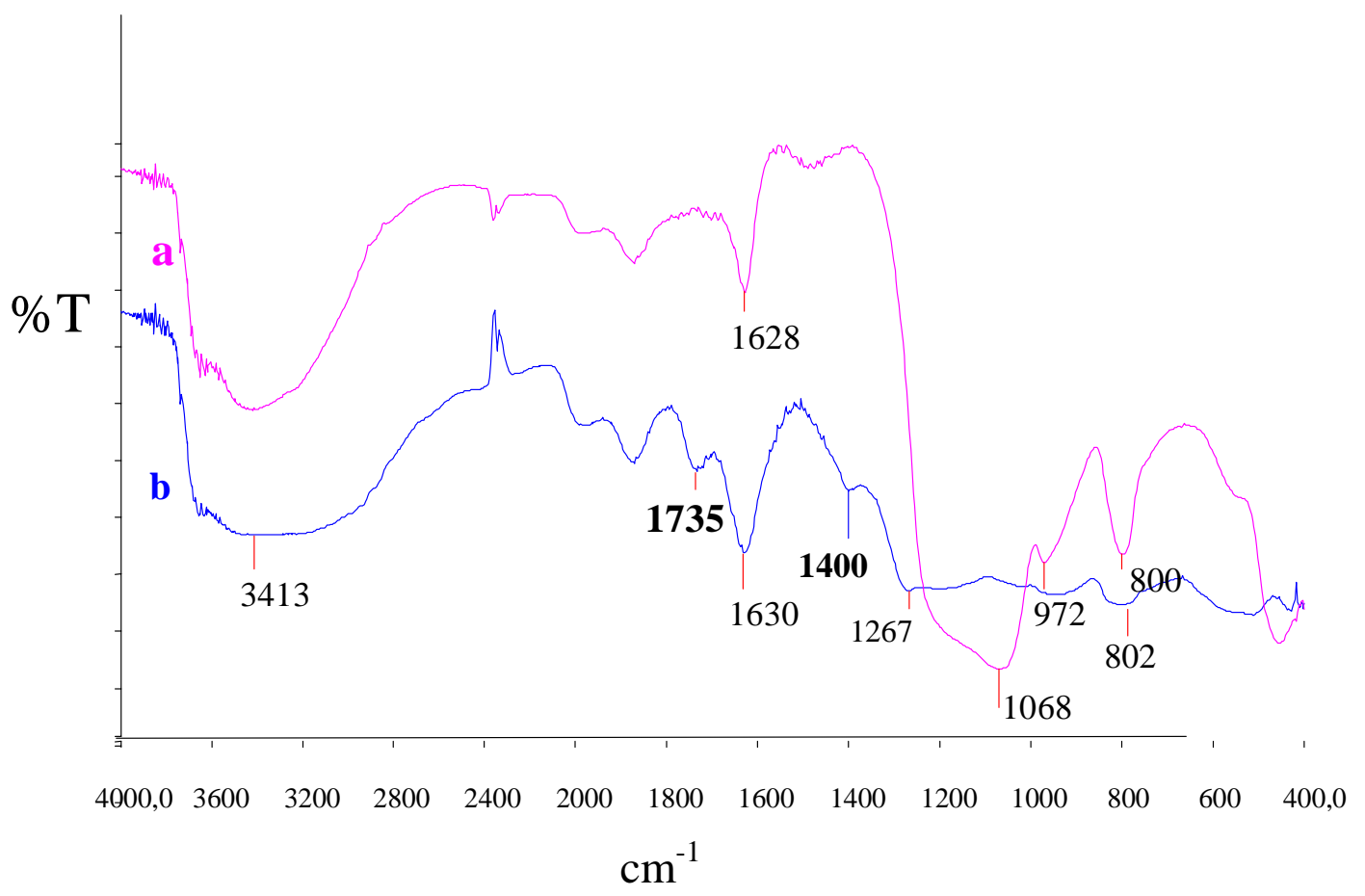

Figure S2: DR-FTIR spectra for $(\alpha) \mathrm{SiO}_{2}$, and (b) the modified $\mathrm{SiO}_{2-}$ $(\mathrm{COOH})_{2}$ material.

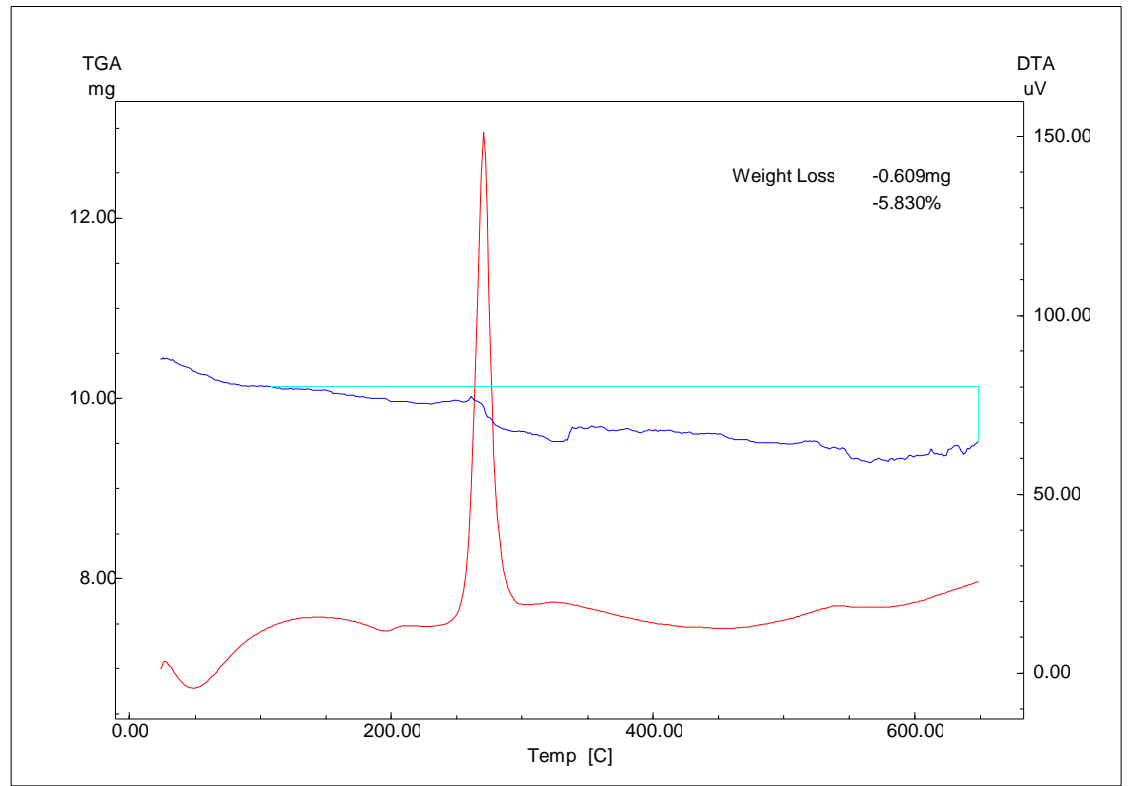

Figure S3: TGA for the modified $\mathrm{SiO}_{2}-(\mathrm{COOH})_{2}$ material (red line). 


\section{Potentiometric titrations}

Surface ionization constants of $\mathrm{SiO}_{2}-[\mathrm{COOH}]_{1}$, Acid-base titration was performed as described earlier (22). 12.5mg material were suspended in a titration cell containing $12.5 \mathrm{mg}$ of Milli-Q water to yield concentration $1 \mathrm{gL}^{-1}$. In the following the suspension was purged with nitrogen gas for $30 \mathrm{~min}$ prior to titration. The alkalimetric titration was done with $12 \mathrm{mM} \mathrm{NaOH}$ and the acidimetric titration was done with $12.5 \mathrm{mM}$ $\mathrm{HNO}_{3}$ solution.

Potentiometric titration of dissolved HA. Humic acid solution with concentration $2 \mathrm{~g} / \mathrm{l}$ with ph 2.5-3 were prepared in the following the solution was purged with nitrogen for $30 \mathrm{~min}$ prior the titration. The titration was done with $0.05 \mathrm{~N} \mathrm{NaOH}$. In all cases then Metrohm 794 Basic Titrino burette was used and the $\mathrm{pH}$ was measured with a Metrohm Pt-glass electrode (type 6.02393.100).
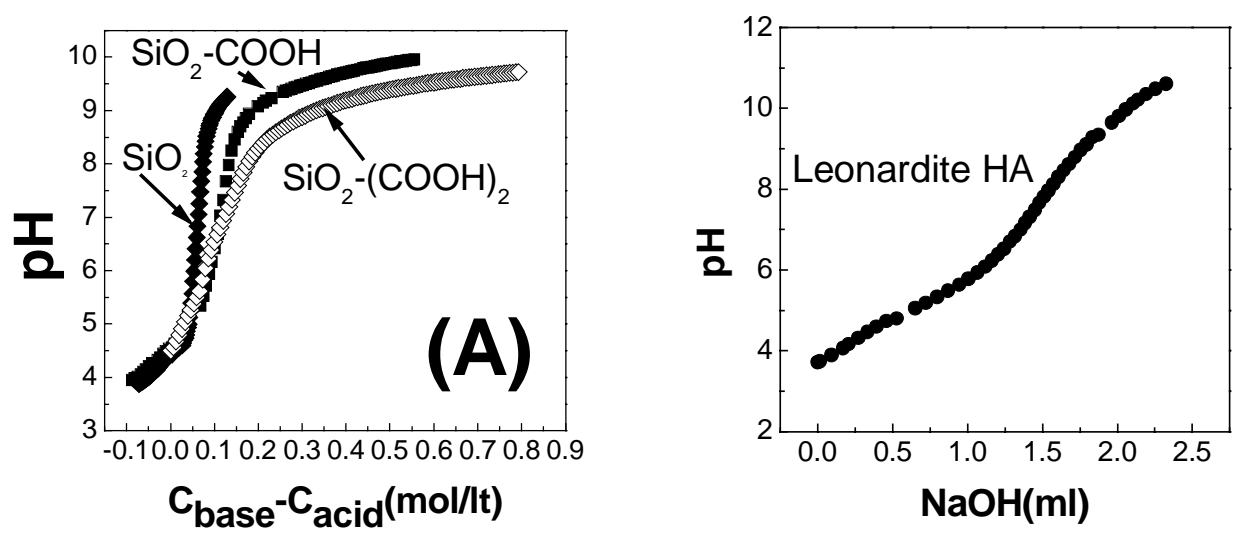

Figure $\mathbf{S 4}(\mathrm{A})$ : Acid-Base potentiometric titrations of $\mathrm{SiO}_{2}, \mathrm{SiO}_{2}-\mathrm{COOH}, \mathrm{SiO}_{2}-$ $(\mathrm{COOH})_{2}(\mathrm{~B})$ : Continuous potentiometric titrations of dissolved Leonardite HA.

Figure S4A shows the potentiometric titration curve for $\mathrm{SiO}_{2}, \mathrm{SiO}_{2}-\mathrm{COOH}$ and $\mathrm{SiO}_{2}-(\mathrm{COOH})_{2}$ respectively. The untreated $\mathrm{SiO}_{2}$, after subtraction of the water background, shows the well known charge surface profile (26). At $\mathrm{pH} 5-8$ the observed plateau is due a slow H-loss from the surface $\mathrm{SiOH}$ groups (26). Then the rabid loss of protons at $\mathrm{pH}>8$ is due the deprotonation of surface $\mathrm{SiOH}$ groups with $\log \mathrm{K}_{1}=7.1$, determined by theoretical fit to the data using FITEQL see table 1 . The deprotonation profile for $\mathrm{SiO}_{2}-\mathrm{COOH}$ differs from $\mathrm{SiO}_{2}$ figure $\mathrm{S} 4 \mathrm{~A}$. At $\mathrm{pH}$ 5-8 the $\mathrm{SiO}_{2}-\mathrm{COOH}$ material requires additional $\mathrm{NaOH}$ in order to deprotonate the surface groups due to the presence of $-\mathrm{COOH}$. In the same context, the deprotonation profile 
for $\mathrm{SiO}_{2}-(\mathrm{COOH})_{2}$ requires even more $\mathrm{NaOH}$, figure $\mathrm{S} 4 \mathrm{~A}$. This is due to the fact that $\mathrm{SiO}_{2}-(\mathrm{COOH})_{2}$ the grafted IMDA, see figure 1, bears two carboxy moieties per molecule. This behavior was quantitatively analyzed by using FITEQL. The optimal fit required the use of more than one $\mathrm{pKa}$ for surface $\mathrm{COOH}$ for both materials. Representative theoretical curves obtained by assuming one, two or more pKa values, this analysis shows that the grafted carboxylates are characterized by a distribution of $\mathrm{pKa}$ values in the range $\mathrm{pKa}=3.8-5.6$ for $\mathrm{SiO}_{2}-\mathrm{COOH}$ and $\mathrm{pKa}=3.4-6.1$ for $\mathrm{SiO}_{2-}$ $(\mathrm{COOH})_{2}$. This phenomenon of distributed pKa values for the same H-bearing molecule is a well documented phenomenon in the case of humic acids e.g. the polyelectrolyte effect. Typically the carboxylic-pKa values in humic acids are found to be distributed in the $\mathrm{pH}$ range 3-5. The present data show that the $\mathrm{pKa}$ distribution of the carboxylic groups in humic acids can be successfully modeled by the $\mathrm{SiO}_{2}$ $(\mathrm{COOH})_{1,2}$ materials.

\section{PART II: Sorption Data}

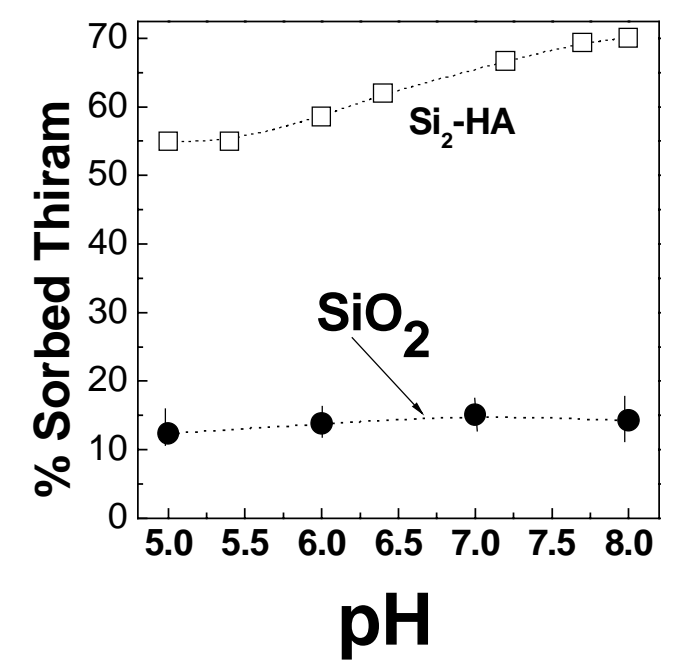

Figure S5. Sorption of $1.57 \times 10^{-5} \mathrm{M}$ thiram on $\mathrm{SiO}_{2}$. The sorption on $\mathrm{SiO}_{2}-\mathrm{HA}$ is also shown for comparison. 


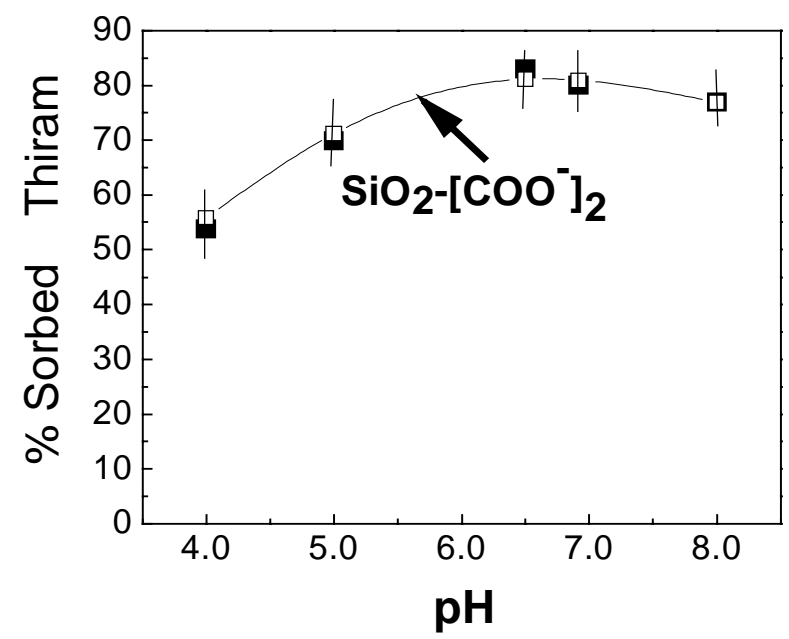

Figure S6. Sorption of $1.58 \times 10^{-5} \mathrm{M}$ of thiram on $\mathrm{SiO}_{2}-[\mathrm{COOH}]_{2}$. Open squares theoretical flit obtained by assuming the reactions listed in Table 1. The deprotonation of the $\left.\mathrm{SiO}_{2[} \mathrm{COOH}\right]_{2}$ occurs at the range of $p K a$ values listed in Table 1.

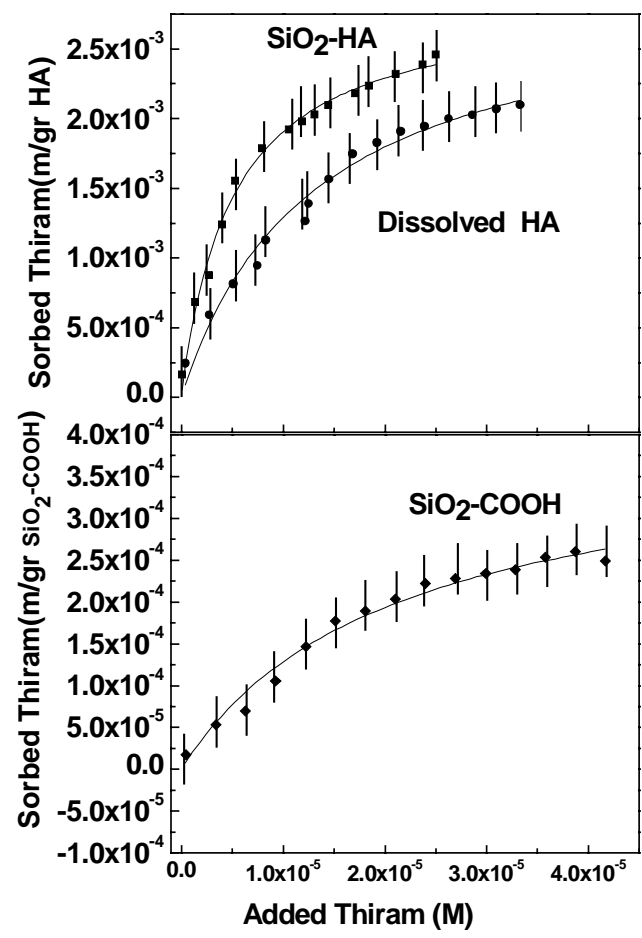

Figure S7. Sorption isotherms for thiram at $\mathrm{pH} 8.0$ on dissolved or immobilized HA (top), and $\mathrm{SiO} 2-\mathrm{COOH}$ material (lower frame). The solid lines are fits to the data by using the Langmuir isotherm. The Langmuir constants used to the fits were $K_{\text {Langmuir }}=0.7$ for immobilized HA, $K_{\text {Langmuir }}=0.4$ for dissolved HA, and $K_{\text {Langmuir }}=0.2$ for $\mathrm{SiO}_{2} \mathrm{COOH}$ 


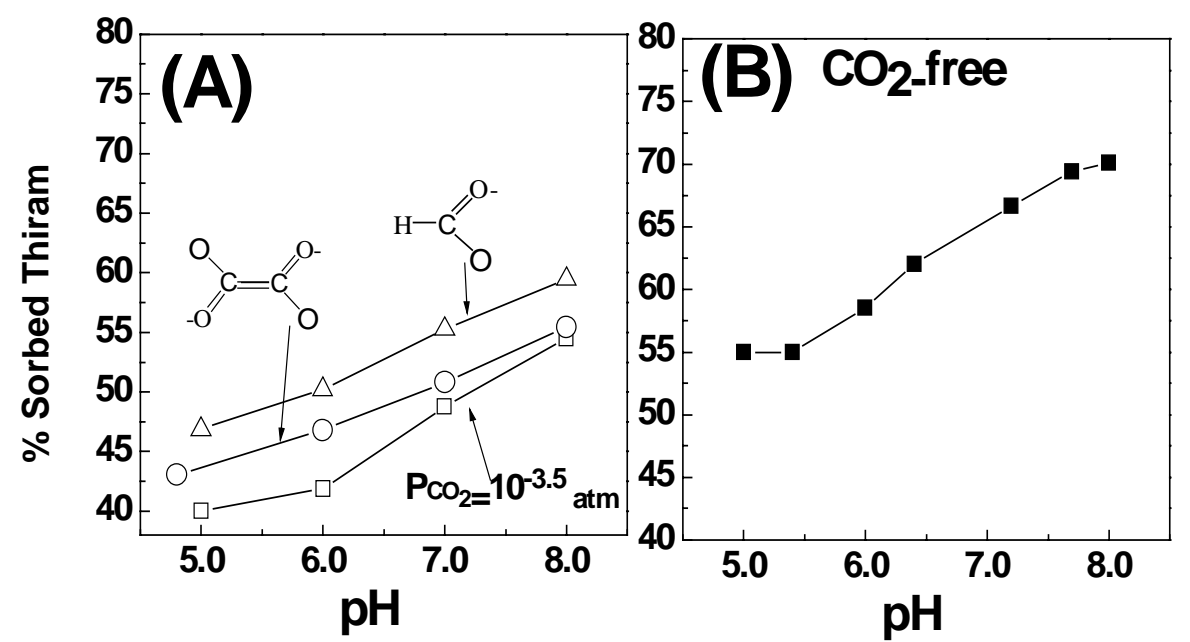

Figure S8. (A) Inhibitory effect of $10 \mathrm{mM}$ Oxalate or Formate on the sorption of $1.6 \times 10^{-5} \mathrm{M}$ thiram on $\mathrm{SiO}_{2} \mathrm{HA}$, in comparison with the effect of ambient $\mathrm{CO}_{2}$. (B) For comparison the sorption under $\mathrm{CO}_{2}$-free conditions is shown.

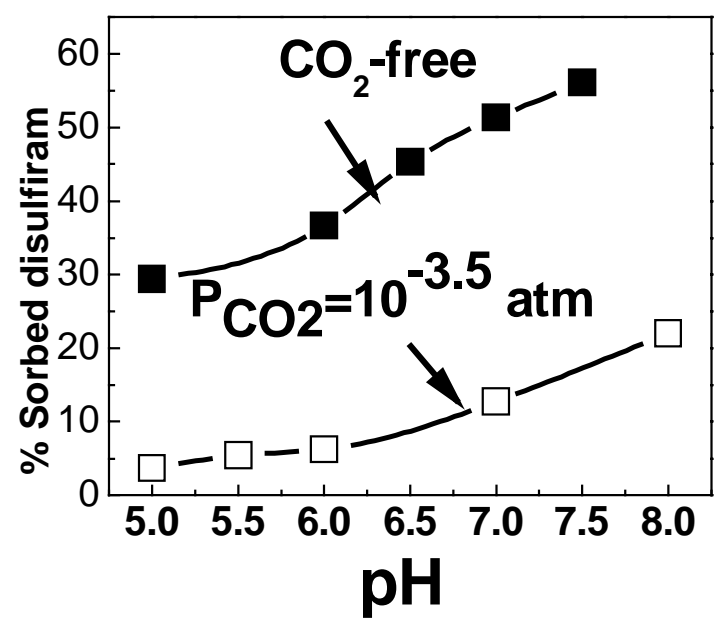

Figure S9 (A) Sorption of $1.65 \times 10^{-5} \mathrm{M}$ disulfiram on $\mathrm{SiO}_{2}$-HA. ( $\mathbf{\square}$ ) in $\mathrm{CO}_{2}$-free solution, $(\square)$ in the presence of $\mathrm{CO}_{2}, \mathrm{P}_{\mathrm{CO} 2}=10^{-3.5} \mathrm{~atm}$. 